\title{
Comparative Evaluation of VSI and CSI based Unified Power Quality Conditioner
}

\author{
K.Vadirajacharya ${ }^{1}$, Pramod Agarwal ${ }^{2}$, H.O.Gupta ${ }^{3}$ \\ (1.Electrical EnggDept, Dr.BATU,Lonere, India) \\ (2.,3Electrical Engg Dept,IIT Roorkee, India)
}

\begin{abstract}
In recent years Unified Power Quality conditioner (UPQC) is being used as universal active power conditioning device to mitigate both current as well as voltage harmonics in a polluted power system network. Both voltage source and current source inverter are in use for fabrication of $U P Q C$. Current source UPQC has unique advantages over generalized voltage source UPQC. This paper presents a comparative analysis of voltage source and current source UPQC. A simple PI controller and robust hystersis band PWM technique is used for derivation of reference and switching signals respectively. The resultant compensation system eliminates voltage as well as current harmonics with good dynamic response. Extensive simulation results using Mat lab / Simulink for $R$-L load connected through an uncontrolled bridge rectifier is presented for performance comparison.
\end{abstract}

Index Terms: CSI, current harmonics, hystersis controller, power quality conditioner, series active filter, shunt active filter, UPQC, voltage harmonics, VSI.

\section{Introduction}

The recent development in power electronics led to development of solid-state controllers, which are in use with industry, commercial and domestic sectors extensively. The quality of power is being deteriorated due to use of these electronic controllers, which in turn demands quality power from source [1]. Varieties of power conditioning techniques are in use starting from passive filtering to active power conditioning [2]. Among different new technical options available to improve power quality, Unified Power Quality Conditioner (UPQC) has found to be more promising. [3]. It provides an important and flexible alternative to compensate both current as well as voltage disturbances simultaneously by a single unit. It is generally configured with two bi-directional converters connected back to back through an energy storage device [3]. Since its development, VSI based UPQC was in use due to its compact size, flexibility to extend multilevel. Different configuration, principle of operation and control of VSI based UPQC is discussed in depth in references [4-6].

With the availability of new IGBT with reverse blocking capability, the use of current source active filters is increasing due to its inbuilt short circuit protection capability, higher efficiency at low power loads, simple open loop current control and effective filtering of harmonics. A configuration and control aspect of current source active power filter is discussed in references [7-8]. Performance of CSI based UPQC is presented by Dusan Graovac etal in 2001[9]. A comparison of current and voltage source shunt active power filters is discussed in past [10-13].

However, comparative analysis of current and voltage source UPQC was missing. This paper presents a comprehensive analysis of current and voltage source UPQC using a simple PI controller for derivation of reference signals. These reference signals are then compared in a robust hystersis controller for generation of switching signals. The differences in system configuration and control strategy are presented in section II and IV. The compensation strategy is discussed in section III. A comparative analysis of simulation results is presented in section $\mathrm{V}$.

\section{System Configuration}

Unified Power Quality Conditioner comprises of two bidirectional converters connected back to back through an energy storage element as shown in fig.1. The generalized UPQC consists of both series and shunt (Voltage /Current) compensation elements. Each element consists of a bidirectional switch to accommodate for voltage or current conversion as per requirement. One of bidirectional converter is connected to system bus in series through a transformer termed as series active filter .It is controlled as voltage generator. It has capability of voltage imbalance compensation, voltage regulation and harmonic compensation at the utility-consumer point of common coupling (PCC). In addition to this, it provides harmonic isolation between a sub transmission system and a distribution system. Another bidirectional converter is connected in parallel with load to the system bus called shunt active filter. 


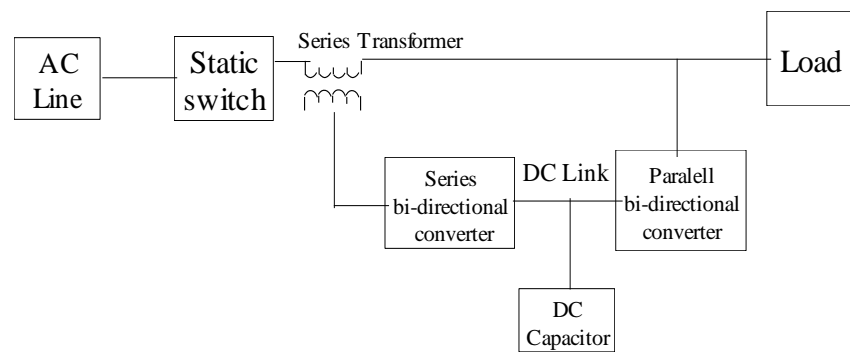

Fig.1. Conceptual diagram of UPQC.

It is controlled as a current generator. It absorb current harmonics, compensate for reactive power and negative sequence current injected by the load. Third element of this power line conditioner is an energy storage device. These bidirectional switches may be of Voltage Source Inverter (VSI) based or Current Source Inverter (CSI) based. Each type of switch is having its own merits and demerits. In current source based UPQC a large inductor is used as a DC link, while in voltage source UPQC a large capacitor is used as energy storage element as shown in fig 2.2 and fig 2.3 respectively. This dc link will function as DC sources and hence does not demand any external power source. However in order to maintain constant DC current/ voltage in the energy storage element a small fundamental current is drawn to compensate active filter losses.

\subsection{SySTEM CONFIGURATION OF VSI BASED UPQC}

A VSI based UPQC is built with two bridges of IGBT switches with anti parallel diode connected back to back with a dc capacitor as energy storage device as shown in fig 2.

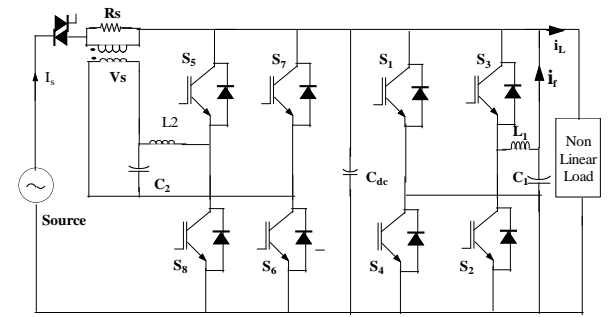

Fig.2. Schematic diagram of VSI based UPQC

The inductor $\mathrm{L}_{\mathrm{f}}$ through which the inverter is connected to power supply network via series transformer, ensures firstly the controllability of the active filter currents and secondly act as first order passive filter attenuating the high frequency ripples generated by the inverter. This filter may also be formed with third order (LCL) type. The voltage of dc capacitor used as energy storage device should be so high that the filter currents can be controlled to draw the load current harmonics through the supply filter. The theoretical minimum value for the voltage is the peak of the supply line-to-line voltage.

\subsection{SYSTEM CONFIGURATION OF CSI BASED UPQC}

A CSI based UPQC is built with two bridges of IGBT switches connected back to back through an inductor of sufficiently large value as shown in fig.3.

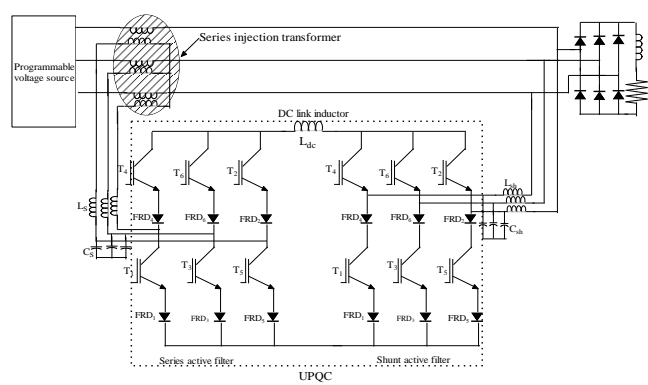

Fig. 3. Schematic diagram of CSI based UPQC

The series filter is connected to $\mathrm{AC}$ mains supply through a series transformer of suitable rating and a second order low pass filter formed by $\mathrm{C}_{\mathrm{f}}$ and $\mathrm{L}_{\mathrm{f}}$. The size of filter capacitor must be selected carefully to make sure that no low-order harmonics are close to the resonant frequency of the LC tank circuit. The switches are under bidirectional voltage stress and maximum values of these are the peak value of the supply line -to-line 
voltage [10]. A Fast Recovery Diode of similar rating is required to connect in series with each switch as to limit reverse voltage blocking. The use of series diode can be avoided by using reverse blocking IGBT. The energy storage element a dc inductor $\mathrm{L}_{\mathrm{dc}}$ is designed to limit the dc current ripple to a specified value to limit ripples in $\mathrm{I}_{\mathrm{dc}}$ The theoretical minimum dc link current is zero, but the current should be at least as high as the peak value of the compensating current. A R-L load connected through diode rectifier bridge will act as non-linear load to verify the system performance.

\section{Compensation Strategy}

The equivalent circuit diagram of an UPQC is as shown in fig $4 \mathrm{Vs}$ is the supply voltage, $\mathrm{Vc}$, and $\mathrm{i}_{\mathrm{c}}$ are the series compensation voltage, shunt compensation current and $\mathrm{V}_{\mathrm{L}}, \mathrm{i}_{\mathrm{L}}$ are the load voltage and load current respectively [15]

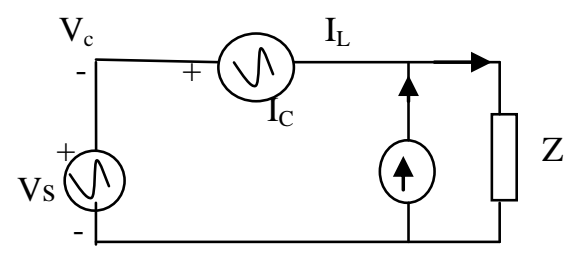

Fig.4. Equivalent circuit diagram of UPQC

The source voltage may contain positive, negative, zero as well as harmonic components. The per phase voltage of the system can be expressed as :

$$
V_{s a}=V_{1 p a}+V_{1 n a}+V_{10 a}+\sum_{k=2}^{\infty} V_{k a} \operatorname{Sin}\left(k \omega t+\theta_{k a}\right)
$$

Where $\mathrm{V}_{1 \mathrm{pa}}$ is the fundamental frequency positive sequence component, $\mathrm{V}_{1 \mathrm{na}}$ and $\mathrm{V}_{10 \mathrm{a}}$ are the negative and zero sequence components respectively. The last term of equation represents the harmonic content in the voltage. In order for the load voltage to perfectly sinusoidal and balanced, the series filter should produce a voltage equal to

$$
V_{a h}=V_{1 n a}+V_{10 a}+\sum_{k=2}^{\infty} V_{k a} \operatorname{Sin}\left(k \omega t+\theta_{k a}\right)
$$

Further the functions of the shunt active filter is to provide compensation of the load harmonic current, load reactive power demand and also to maintain DC link current constant. The per phase load current of shunt active filter is expressed as

$$
\begin{aligned}
& i_{a l}=i_{a 1 p} \operatorname{Cos}\left(\omega t-\theta_{1}\right)+i_{a \mathrm{ln}}+\sum_{k=2}^{\infty} i_{a l k} \\
& i_{a l}=i_{a 1 p} \operatorname{Cos} \omega t \operatorname{Cos} \theta_{1}+i_{a 1 p} \operatorname{Sin} \omega t \operatorname{Sin} \theta_{1}+i_{a \mathrm{ln}}+\sum_{k=2}^{\infty} i_{a l k}
\end{aligned}
$$

In order to compensate harmonic current and reactive power demand the shunt active filter should produce a

current of $i_{a h}=i_{a 1 p} \operatorname{Sin} \omega t \operatorname{Sin} \theta_{1}+i_{a \ln }+\sum_{k=2}^{\infty} i_{a l k}$

So the source current will be

$$
i_{a s}=i_{a l}-i_{a h}=i_{a 1 p} \operatorname{Cos} \omega t \operatorname{Cos} \theta_{1}
$$

This is a perfect harmonic free sinusoidal current in phase with voltage.

\section{CONTROL STRATEGY}

The control strategy has been implemented in two parts:

\subsection{SERIES FILTER CONTROL}

In both current source and voltage source UPQC, the series filter is controlled by similar hystersis band voltage control. A series active filter acts as controlled voltage source by imposing high impedance for the harmonic currents, blocking their flow from both loads to source and source to load directions. The source voltage may contain zero, negative sequence as well as harmonic component, which need to be eliminated by series compensator. In order for the load voltage to perfectly sinusoidal and balanced, the series filter should produce a voltage equal to equation (2). The reference load voltages are obtained by multiplying a PLL based unit vector templates with a constant equal to peak amplitude of fundamental input voltage [13]. Unit vector templates for different phases are obtained with proper phase delay as follows: 


$$
\left.\begin{array}{l}
u_{a}=\operatorname{Sin} \omega t \\
u_{b}=\operatorname{Sin}\left(\omega t-120^{0}\right) \\
u_{c}=\operatorname{Sin}\left(\omega t+120^{0}\right)
\end{array}\right\}
$$

These compensation signals are compared with actual signals at the terminals of series filter, the error is then taken to hystersis controller to generate the required gating signal for series filter. The control block diagram of series filter is as shown in fig 5

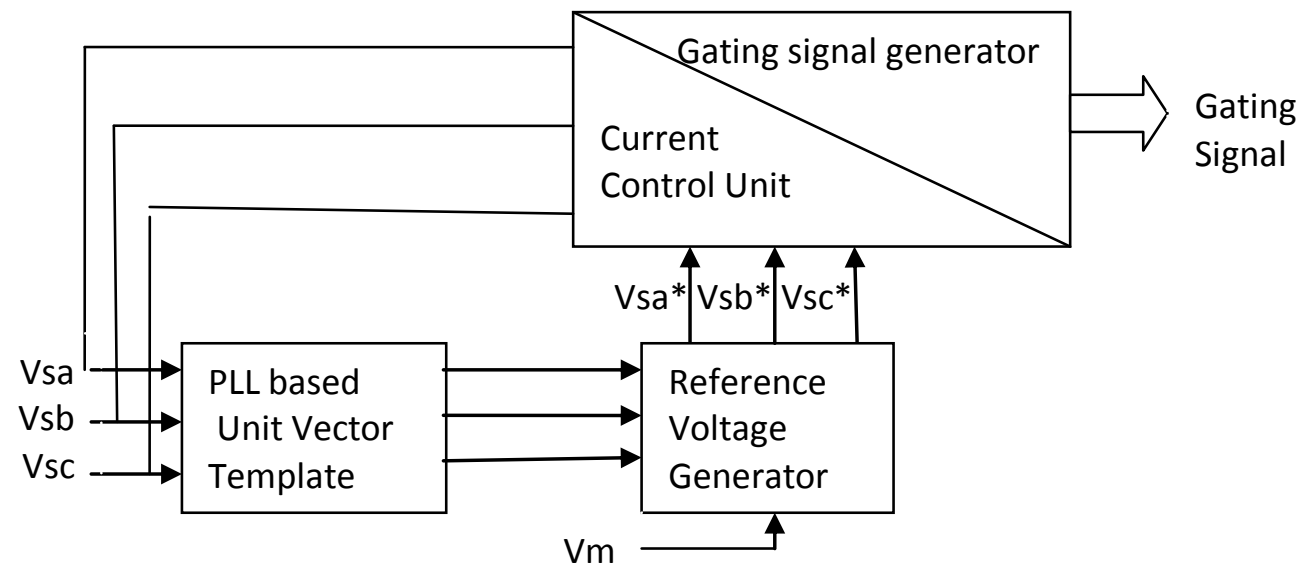

Fig.5.Control block diagram of series filter.

\subsection{SHUNT FILTER CONTROL}

The main purpose of the shunt active filter is to absorb current harmonics, compensate for reactive power and negative sequence current injected by the load. In addition, it controls current / voltage of the DC link to a desired value.

\subsubsection{Voltage SOURCE UPQC}

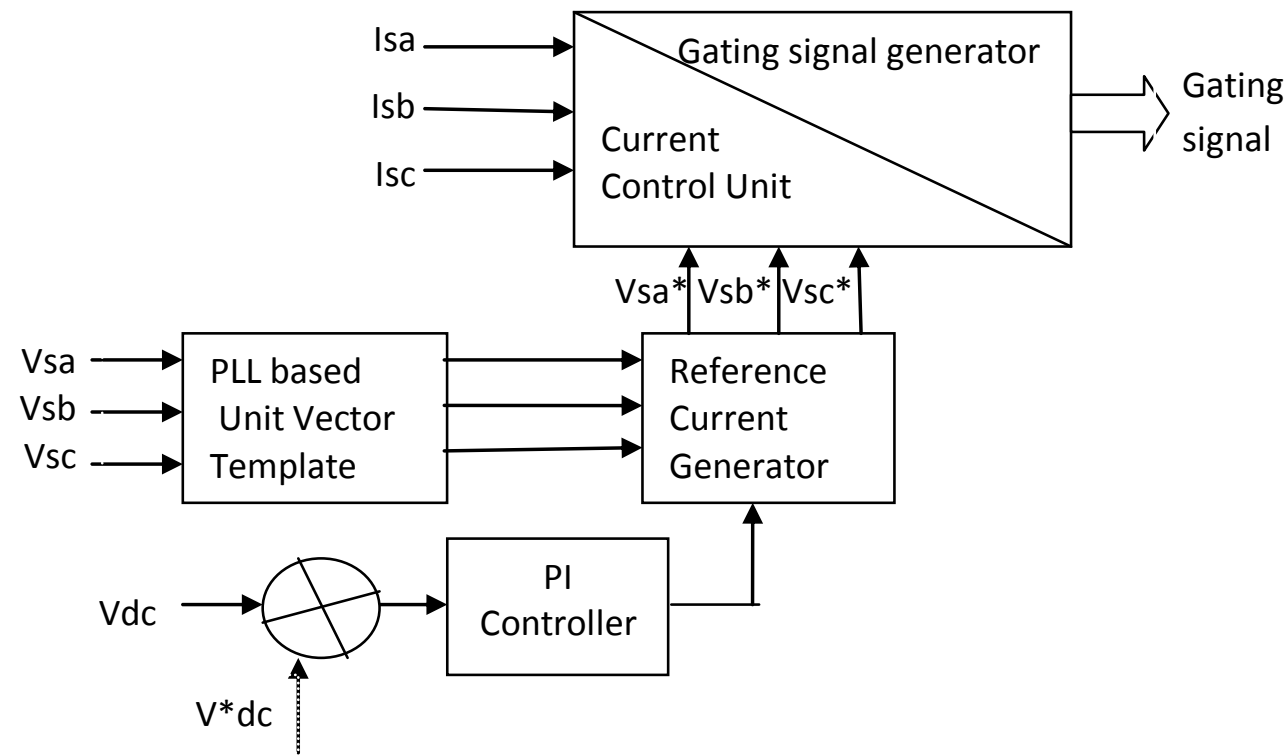

Fig.6.VSI based UPQC shunt filter controller 
In case of voltage source UPQC, the dc link voltage is sensed and compared with the reference dc link voltage. A PI controller then processes this error. Output signal from PI controller is regarded as magnitude of three phase reference currents. Reference supply currents are then obtained by multiplying unit vectors template with magnitude of reference current. The source current must be equal to this reference supply currents. In order to follow this reference current signal, the source currents are sensed and compared with reference current signals. The error generated is then processed by hystersis current controller with suitable band, generating gating signals for shunt filter [13]. The control diagram of VSI based shunt filter controller is as shown in fig.6

\subsubsection{CURRENT SOURCE UPQC}

In case of CSI based UPQC, the dc link current is sensed and compared with reference dc link current. A PI controller then processes the error. The output signal from PI controller is regarded as switching power losses of shunt active filter, and is added to real power loss component to derive reference source current using equations 9- 15. These reference currents are then compared with actual source current in a hystersis controller band to derive the switching signals of shunt inverter. The schematic block diagram of shunt filter controller is shown in fig.7

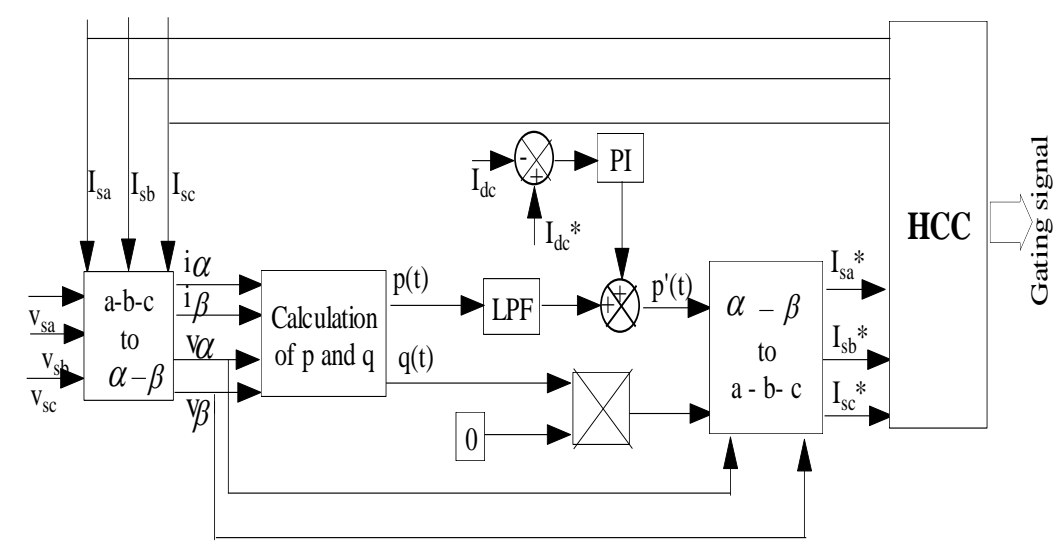

Fig.7. CSI based UPQC shunt filter controller

$$
\begin{aligned}
& {\left[\begin{array}{l}
v_{\alpha} \\
v_{\beta}
\end{array}\right]=\left[\begin{array}{ccc}
1 & -1 / 2 & -1 / 2 \\
0 & \sqrt{3} / 2 & -\sqrt{3} / 2
\end{array}\right]\left[\begin{array}{l}
v_{a} \\
v_{b} \\
v_{c}
\end{array}\right]} \\
& {\left[\begin{array}{l}
i_{\alpha} \\
i_{\beta}
\end{array}\right]=\left[\begin{array}{ccc}
1 & -1 / 2 & -1 / 2 \\
0 & \sqrt{3} / 2 & -\sqrt{3} / 2
\end{array}\right]\left[\begin{array}{l}
i_{a} \\
i_{b} \\
i_{c}
\end{array}\right]}
\end{aligned}
$$

Instantaneous active and reactive power in orthogonal co-ordinates are calculated as follows

$$
\begin{aligned}
& p(t)=v_{a}(t) i_{a}(t)+v_{b}(t) i_{b}(t)+v_{c}(t) i_{c}(t) \\
& p(t)=v_{\alpha}(t) i_{\alpha}(t)+v_{\beta}(t) i_{\beta}(t) \\
& q(t)=-v_{\beta}(t) i_{\alpha}(t)+v_{\alpha}(t) i_{\beta}(t)
\end{aligned}
$$

In matrix form it is given as

$$
\left[\begin{array}{l}
p \\
q
\end{array}\right]=\left[\begin{array}{cc}
v_{\alpha} & v_{\beta} \\
-v_{\beta} & v_{\alpha}
\end{array}\right]\left[\begin{array}{l}
i_{\alpha} \\
i_{\beta}
\end{array}\right]
$$

From (9) the values of $\mathrm{p}$ and $\mathrm{q}$ can be expressed in terms of dc components plus the ac components as follows $p=\bar{p}+\tilde{p}$

$q=\bar{q}+\tilde{q}$

Where

$\bar{p}$ is the dc component of the instantaneous power $\mathrm{p}$, and is related to, the fundamental active current. 
$\tilde{p}$ is the ac component of the imaginary power $\mathrm{p}$, and is related to the harmonic current caused by the ac component of the instantaneous real power.

$\bar{q}$ is the dc component of the imaginary instantaneous power $\mathrm{q}$, and is related to the reactive power generated by the fundamental components of voltage and current.

$\tilde{q}$ is the ac component of the instantaneous imaginary power $\mathrm{q}$, and is related to the harmonic current caused by the ac component of instantaneous reactive power .

To compute harmonic free unity power factor, 3-phase currents, compensating powers $\mathrm{p}_{\mathrm{c}}$ and $\mathrm{q}_{\mathrm{c}}$ are selected as

$p_{c}=\bar{p}+p_{\text {loss }}$

$q_{c}=0$

Where $\mathrm{p}_{\text {loss }}$ is the instantaneous active power corresponding to the switching loss and resistive loss of shunt active filter. Total instantaneous active power is calculated by adding real power loss due to switching as shown in fig.7 [12].The orthogonal components of the fundamental current are obtained as follows.

$\left[\begin{array}{l}i_{\alpha} \\ i_{\beta}\end{array}\right]=\left[\begin{array}{cc}v_{\alpha} & v_{\beta} \\ -v_{\beta} & v_{\alpha}\end{array}\right]^{-1}\left[\begin{array}{l}p_{c} \\ q_{c}\end{array}\right]$

The a-b-c components of fundamental reference current are obtained as follows.

$$
\left[\begin{array}{l}
i^{*}{ }_{s a} \\
i^{*}{ }_{s b} \\
i^{*}{ }_{s c}
\end{array}\right]=\left[\begin{array}{cc}
2 / 3 & 0 \\
-1 / 3 & 1 / \sqrt{3} \\
-1 / 3 & -1 / \sqrt{3}
\end{array}\right]\left[\begin{array}{l}
i_{\alpha} \\
i_{\beta}
\end{array}\right]
$$

The control of both VSI and CSI based UPQC is realized using hystersis band PWM technique. Among various PWM techniques, the hystersis band control is used very often because of its simplicity of implementation, fast response and does not need any knowledge of load parameters. The basic implementation of hystersis control is based on deriving the switching signals from comparison of the signal error with a fixed tolerance band.

\section{Comparison Based On Simulation Results}

To verify the performance, both VSI based and CSI based UPQC model is developed using above equations in MATLAB / SIMULINK. A three-phase diode rectifier with an RL load is employed as nonlinear load. All the compensators are implemented using equivalent discrete blocks. Shunt filter is switched on at 0.05 $\mathrm{sec}$, while series filter is switched on at $0.1 \mathrm{sec}$ to verify the performance of indusial filters. Controlled switches are assumed ideal. The system parameters are selected as given in table 1

TABLE-1

SYSTEM PARAMETER

\begin{tabular}{|l|l|}
\hline Supply & $\begin{array}{l}3 \Phi .50 \mathrm{~Hz}, 100 \mathrm{Vp}-\mathrm{p} \text { with } \\
20 \% \text { of } 5^{\text {th }} \text { harmonics }\end{array}$ \\
\hline Load(Non-linear) & $(10+\mathrm{j} 7.85) \Omega$ \\
\hline Line inductance & $50 \mu \mathrm{H}$ \\
\hline Line resistance & $0.01 \Omega$ \\
\hline Switching frequency & $\sim 20 \mathrm{kHz}$ \\
\hline Sample time & $1 \mu \mathrm{sec}$ \\
\hline Smoothing inductance & $1 \mathrm{mH}$ \\
\hline
\end{tabular}

The filter parameters for VSI and CSI based UPQC are selected as given in table 2

TABLE-2

FILTER PARAMETER

\begin{tabular}{|l|l|l|l|}
\hline VSI & CSI \\
\hline DC Link Capacitance & $450 \mu \mathrm{F}$ & DC Link inductance & $450 \mathrm{mH}$ \\
\hline Series filter reactance $\mathrm{L}_{\mathrm{SC}}$ & $5 \mathrm{mH} ., 0.1 \Omega$ & Series filter reactance $\mathrm{C}_{\mathrm{sc}}$ & $0.4 \mu \mathrm{F}, 1 \Omega$ \\
\hline Shunt filter reactance $\mathrm{L}_{\mathrm{sh}}$ & $5 \mathrm{mH}, 0.4 \Omega$ & Shunt filter reactance $\mathrm{C}_{\mathrm{sh}}$ & $240 \mu \mathrm{F}, 1 \Omega$ \\
\hline
\end{tabular}

The performance of shunt and series filter of VSI based UPQC is shown in fig 8 and fig.9, while that of CSI based UPQC is presented in fig 10 and fig. 11 respectively. 


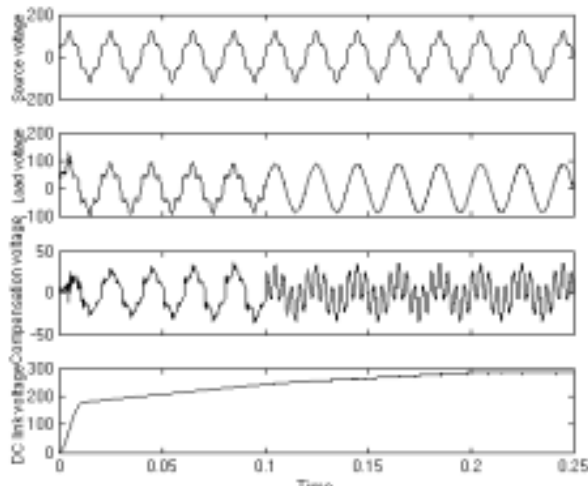

Fig .8. Source voltage, load voltage, compensation voltage and dc link voltage of VSI based UPQC
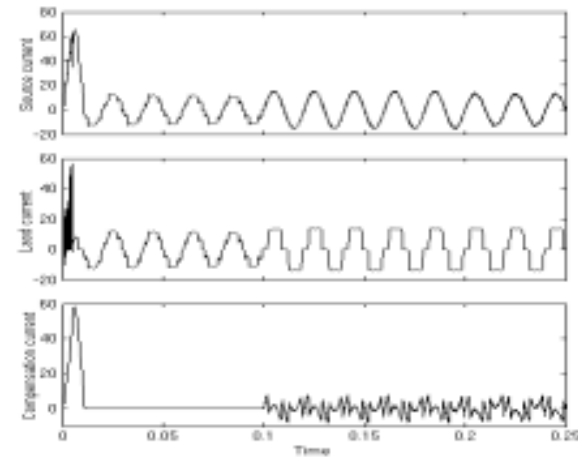

Fig..9 Source current, load current and filter current of VSI based UPQC

The performance of UPQC for voltage harmonic correction is depend upon the series filter performance. The load voltage is same as source voltage, till the series filter is switched on. The instant at which series filter is switched on ie at $0.1 \mathrm{sec}$, the load voltage becomes pure sinusoidal as indicated in fig. 8 and fig.9. Hence compensating for voltage harmonics present in the system and thus, corrects the system voltage to be pure sinusoidal at PCC irrespective of voltage distortions present at the source. The performance difference between VSI and CSI based UPQC is that the THD of load voltage at PCC improves to $1.15 \%$ in case of VSI while in CSI it improves to $1.13 \%$ from $20 \%$ of 5 th harmonic distortion at source which is well below the IEEE recommended harmonic

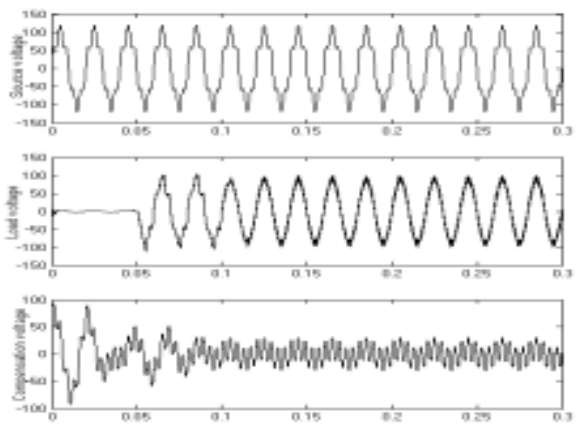

Fig.10. Source voltage, load voltage and filter voltage of CSI based UPQC

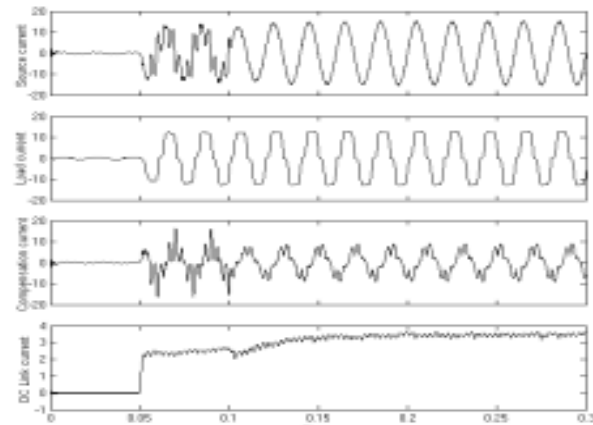

Fig.11 Source current, load current, filter current and DC link current of CSI based UPQC 
Further, the capability of UPQC for current harmonics correction and reactive power compensation is adjudged by the performance of shunt filter. The shunt filter performs satisfactorily only under balanced voltage conditions, which can be verified from fig 9 and fig. 11 in which even though shunt filter is switched on at $0.5 \mathrm{sec}$, because of voltage unbalance fails to compensates satisfactorily for current harmonics. However, after series filter is switched on, the shunt filter starts to compensate for current harmonics. With the integrated operation of shunt and series filter, the THD of source current in VSI configuration improves from $15.62 \%$ to 1.62 , however in case of CSI the THD of source current improves from $15.55 \%$ to $1.01 \%$ again which is well below IEEE 519 standards. A comparative harmonic spectrum analysis of both VSI and CSI is presented in table 3 .

TABLE-3

HARMONIC SPECTRUM ANALYSIS

\begin{tabular}{|c|c|c|c|c|c|c|c|c|}
\hline \multirow{3}{*}{$\begin{array}{l}\text { Harmonic } \\
\text { order }\end{array}$} & \multicolumn{8}{|c|}{ Amplitude } \\
\hline & \multicolumn{2}{|l|}{$\mathrm{I}_{\mathrm{s}}$} & \multicolumn{2}{|l|}{$\mathrm{I}_{\mathrm{L}}$} & \multicolumn{2}{|l|}{$\overline{V_{s}}$} & \multicolumn{2}{|l|}{$\mathrm{V}_{\mathrm{L}}$} \\
\hline & CSI & VSI & CSI & VSI & CSI & VSI & CSI & VSI \\
\hline Fundamental & 14.7 & 14.3 & 13.6 & 13.3 & 100 & 100 & 87.8 & 87.5 \\
\hline $5^{\text {th }}$ & 0.06 & 0.12 & 1.90 & 1.90 & 20.0 & 20.0 & 0.86 & 0.72 \\
\hline $7^{\text {th }}$ & 0.02 & 0.04 & 0.86 & 0.87 & 0.0 & 0.0 & 0.32 & 0.42 \\
\hline $11^{\text {th }}$ & 0.03 & 0.04 & 0.28 & 0.27 & 0.0 & 0.0 & 0.16 & 0.13 \\
\hline $13^{\text {th }}$ & 0.03 & 0.04 & 0.21 & 0.21 & 0.0 & 0.0 & 0.10 & 0.16 \\
\hline $17^{\text {th }}$ & 0.01 & 0.03 & 0.12 & 0.12 & 0.0 & 0.0 & 0.01 & 0.03 \\
\hline $19^{\text {th }}$ & 0.01 & 0.04 & 0.09 & 0.09 & 0.0 & 0.0 & 0.04 & 0.05 \\
\hline THD $(\%)$ & 1.01 & 1.62 & 15.5 & 15.6 & 20.0 & 20.0 & 1.13 & 1.15 \\
\hline
\end{tabular}

From the above table it is clear that CSI performance better than VSI with respect to harmonic filtration at the designated load. The transient stability of the system is adjudged by DC link oscillations present in the filtering system. VSI based UPQC has problem of slow control of converter as compare to that of CSI based UPQC that is evident from fig 5.1 and fig 5.4. VSI based UPQC takes $100 \mathrm{~ms}$ to reach dc link voltage to a stable value, while CSI based UPQC reaches stable value with in $50 \mathrm{~ms}$ indicating superior functionalities over VSI counterpart.

\section{CONCLUSION}

The performance of CSI and VSI based UPQC is studied. Both the system is operated at a switching frequency of $20 \mathrm{kHz}$ approximately, and is connected to same type of supply system. For the study purpose both systems are connected to a nonlinear load of $(10+j 7.85)$ through a diode rectifier. The study reveals that the performance of CSI based UPQC is better as compared with VSI based UPQC. At a fixed switching frequency, the THD of source current and load voltage of CSI based UPQC is less than that of VSI based UPQC. Moreover, the increased oscillations in VSI based system may result in poor transient stability. Hence, it is concluded that the performance of CSI based UPQC is better in comparison with that of VSI based UPQC.

\section{References}

[1] S.L.Clark, P.Famouri and W.L.Cooley, "Elimination of supply harmonics: an evolution of current compensation and active filtering methods", IEEE, IAS 94, Denver, Colorado, USA,Oct.1994, pp-1699-1704

[2] Bhim Singh,Kamal.A.H., and Ambrish Chandra, "A Review of Active Filters for Power Quality improvement", IEEE Transactions on Industrial Electronics, Vol-46,No-5, October 1999,pp 960-971.

[3] Vadirajacharya.K, Pramod Agarwa and H.O.Gupta, "A Simple Control Strategy for Unified Power Quality Conditioner Using Current Source Inverter" $8^{\text {th }}$ International Power Engineering Conference - IPEC2007 3-6 December 2007, Singapore

[4] H. Fujita, H. Akagi, Unified Power Quality Conditioner: The Integration of Series and Shunt Active Filter, IEEE Trans. on Power Electronics, vol.13, no.2, March 1998, pp.315-322.

[5] M.Ardes, K.Heuman and E.Watanabe, “An Universal active power line conditioner”, IEEE Transactions on Power delivery , Volume13, No2,Apr 1998,pp545-551

[6] Ghosh and G. Ledwich, "A unified power quality conditioner (UPQC) for simultaneous voltage and current compensation," Electric Power Systems Research, Vol. 59,2001, pp. 55-63

[7] Y.Hayashi, N. Sato and K. Takahashi, "A novel control of a current source active filter for ac power system harmonic compensation”, IEEE Transactions on Industry Application, Vol.27, No.2, Mar/Apr 1997, pp.380-385

[8] Salo. M., Tuusa. H., "A new control system with a control delay compensation for a current-source active power filter" IEEE Transactions on Industrial Electronics, vol 52,No.6. Dec 2005 pp1616-1624

[9] D.Graovac, V. Katic, Alfred Rufer, Jovan Kne evi Baldor ASR GmbH, "Unified Power Quality Conditioner based on Current Source Converter topology" EPE 2001 - Graz ,pp 1-9

[10] M. Salo, \& H.Tuusa, “Comparison of voltage-source and current-source shunt active power filters", IEEE 36th Annual PES Conference, PESC05, June 12-16, 2005, Recife, Brazil. pp. 2571-2577

[11] L. Benchaita, S. Saadate and A Salem nia, "A comparison of voltage source and current source shunt active filter by simulation and experimentation" IEEE Transactions on Power Systems, Vol.14, No.2, May 1999, pp 642-647.

[12] H. L Yunus and R. M. Bass, "Comparison of VSI and CSI topologies for single phase active power filter", IEEE PESC'96, pp. 1892-1899.

[13] V. Khadkikar, P. Agarwal, A. Chandra, A.O. Bany and T.D. Nguyen, "A Simple New Control Technique For Unified Power Quality Conditioner (UPQC)", 2004 11th International Conference on Harmonics and Quality of Power, Lake Placid, New York, USA, Sept 12-15 2004, pp 289-293. 